\title{
The Myth of the Present Moment
}

\section{Ronald Purser}

Published online: 12 August 2014

(C) Springer Science+Business Media New York 2014

Jon Kabat-Zinn has operationally defined mindfulness as "the awareness that arises from paying attention, on purpose, in the present moment, and non-judgmentally." This operational definition, which informs mindfulness-based stress reduction (MBSR), has not only become the gold standard in the clinical literature but also the media and general populace has latched on to it as a definitive description. Even the manner in which the clinical and contemplative science community views mindfulness has been tremendously influenced by this operational definition. The practice of cultivating present moment awareness, as much of the research on MBSR suggests, has demonstrated therapeutic value for reducing stress and a variety of other symptoms fueled by excessive rumination. Quieting the mind and dispassionately observing the flow of experience is conducive to the deautomization of habitual reactions (Vago 2013; Vago and Silbersweig 2012).

Clearly, MBSR has many therapeutic benefits when it comes to alleviating stress-related symptoms and disorders. However, I propose that MBSR's present-moment focused operational definition limits the depth and potential of secular mindfulness practice to further investigate the temporal structure of suffering, or dukkha, at a fundamental level. In the Buddhist teachings, there are three forms or levels of suffering: the suffering of suffering (dukkha-dukkhata); the suffering of change (viparinama-dukkhata); and the suffering of conditioned existence or all pervasive suffering (samkharadukkhata). Suffering of suffering is gross level suffering, which MBSR and most therapeutic mindfulness modalities address - chronic pain, anxiety, stress, depression. I refer to this form of suffering as "first-level" suffering. The Buddha referred to the "two arrows" of suffering-physical and

R. Purser $(\bowtie)$

Department of Management, San Francisco State University, San Francisco, CA 94132, USA

e-mail: rpurser@sfsu.edu mental pain, and elaborative mentation about actual pain. Physical and mental pain, as the Buddha pointed out, may at times be unavoidable. Mental elaborative pain, however, is a reactive and judgmental response to unpleasant physical sensations or to situations we deem should not be happening.

The suffering of change, or "second-level" suffering, is apparent in that any phenomena that arises will also pass away, is subject to change, and not permanent. This is sometimes referred to as the suffering derived from a reversal of fortune. Second-level of suffering is poignant when we cling tightly to situations or grasp at pleasurable experiences in the hopes that they will never change. We may also seek pleasure to avoid pain, or chase after experiences we believe will bring us lasting happiness, but they eventually disappoint. Such seeking of hedonic pleasure is itself a source of stress and anxiety.

The suffering of conditioned existence, or "third-level" suffering, is actually the basis of the previous two levels of suffering. It is a much more subtle level of suffering, based on the premise that any phenomena that takes form or birth is subject to the laws of karma and dependent origination. This deepest level of all pervasive suffering is rooted in a fundamental delusion, or fixed view, that the existence of a person in a world is a continuous being from the time of birth (until death). Hence, it is the deepest level of existential suffering, or angst, which is haunted by a sense of lack, or a vague and gnawing feeling, that deep down, a primal fear that self may be groundless, empty, and devoid of a permanent and separate identity (Loy 2000). This level of suffering is usually repressed, or covered up, through incessant goal-directed activity that are attempts to make the self feel more secure, grounded and real. The suffering of conditioning, or "third-level" suffering, requires the deepest level of investigation of temporality which therapeutic mindfulness is not designed to do.

While it is true that MBSR and other forms of therapeutic mindfulness interventions aim to reduce suffering - which is 
resonant with Buddhist practice - we have to be more discerning and accurate in what is meant by suffering, in terms of its different levels and forms, as it is understood within the Buddhist tradition. As pointed out above, therapeutic mindfulness is limited to the alleviation of first-level suffering, in terms of mental stress and emotional pain, and other psychosomatic symptoms. Dorjee (2014, p. 118) pointed out that the main emphasis of secular mindfulness practice "is on basic enhancement of attentional stability and the development of nonjudgmental meta-awareness in order to improve people's abilities to cope with everyday stresses and anxieties."

The practice of Buddhist mindfulness, however, is not limited to symptom reduction at the first-level of suffering. The penetration into the true nature of the self, to see through the delusion of its inherent existence (annatta), is a cornerstone of Buddhist philosophy. The Buddhist teachings consider basic ignorance (avidya) as the root cause of mental and emotional afflictions (kleshas). However, this form of ignorance is not a mere lack of knowledge, but a deeply instinctive sense of an unchanging, separate self or "I"- which requires a particular temporal order in which to operate. I will explain why mindfulness approaches which use instructions to "pay attention to the present moment non-judgmentally" not only leaves the conventional temporal structure of suffering intact but also lacks efficacy for the cultivation of penetrating wisdom and insight.

While participating in an MBSR course, I was struck how often the present moment was presented as an object of meditation. The Theravada and Zen traditions approach the present moment and the investigation of a temporal order of suffering quite differently. For this comparative analysis, I draw on both classic Theravada canonical sources and the writings of Dōgen, a 13th Japanese Zen master, and founder of the Soto Zen school, as well as the visionary and secularized work of Tarthang Tulku, a Tibetan lama.

In MBSR, cultivation of mindfulness is aimed at redirecting attention to the present moment, which reduces mental ruminations about the past and future. I refer to this mode of mindfulness training as "therapeutic mindfulness." This method also encourages cultivating an attitude of fully appreciating the intensity of experience, or "radically accepting" (Brach 2004) whatever arises with "affectionate attention." In this respect, the emphasis on fully appreciating and paying attention to the present moment is a mode of sensory enhancement; it is an instruction on how to relate to the immediacy of personal experience by fully embracing and accepting it without bias or judgment.

Therapeutic mindfulness approaches the present moment as way to become more appreciative and aesthetically aware of the beauty in ordinary, mundane experiences. In MBSR parlance, this is referred to as "dropping into" the "being mode." A good caricature of the being mode is the mindful eating of a raisin, one of the first MBSR exercises that newcomers, and which I, was asked to do. This exercise is revealing as it clearly illustrates that if you are mindful of eating the raisin, you will experience it richly, aware of the present sensations and pleasures it evokes. You will know the raisin in a different way because you have brought to life the act of eating it. This is the epistemological aspect of meditation, rooted in experience as a way of knowing. However, there is no fundamental ontological shift in being, no radical transformation of the self, or the one who knows. In other words, we are eager to deepen our experience (to bring it back to life), but there is no radical questioning the nature of what we hold to be true. We are open to appreciating more fully what happens, but not to challenging our understanding of what is happening - especially in a temporal sense.

Rather than developing insight into the temporality of change and suffering, or questioning why present moment experiences are fleeting, we are advised to develop an acceptance of the inconstancy of our experience with stoic equanimity and a nonjudgmental attitude. Clearly, developing mindfulness of the present moment encourages an appreciation of fleeting experiences and may also grant some temporary relief from excessive mental ruminations and the tribulations of life. However, the mental relief or heightened aesthetic appreciation gained from present-moment focused mindfulness will still be conditioned by the temporality of change - by second and third-level suffering. Because any conditioned formation and experience that arises is subject to change, is inconstant, and of the nature of suffering - this includes the present moment.

In a clinical and therapeutic context, mindfulness is also presented as a problem-solving technique, or a means to achieve some desired end. For example, numerous mindfulness-based interventions have been developed with specific therapeutic goals: depression relapse prevention, prevention of relapse following rehabilitation of substance abuse, treatment of binge and eating disorders, cessation of smoking, treatment of PTSD, improving quality of life for cancer patients, treatment of mood disorders, mindfulness-based child birth, parenting, and elder care, and many more. This mode of therapeutic, problem-solving mindfulness is aimed at achieving ends that the self-as-agent (and clinician administering the treatment program) deems worthy of achieving in advance. Mindfulness put to work in this way does its job admirably in reducing and ameliorating first-level suffering through achieving its therapeutic aims and goals. However, this form of programmatic symptom reduction rarely includes an inquiry into the nature of the subject, or self, who is suffering. Some approaches, such as mindfulness-based cognitive therapy (MBCT) and MBRP (which are taught by trained mental health professionals, rather than lay people), do devote some inquiry and attention into the nature of suffering, craving/ aversion, but even these mindfulness-based interventions are 
focused on very specific therapeutic aims and outcomes. Given the circumscribed aims of therapeutic mindfulness, such a deep inquiry into the nature of the self would be inappropriate, out of place, and even risky to a clinical population that is not prepared to undergo what could potentially be an extremely unsettling and destabilizing experience (Kaplan et al. 2012).

Along with its lack of capacity to critically question the temporality of change, there are many unquestioned temporal assumptions inherent in MBSR and mindfulness-based interventions (MBIs). A phenomenological inquiry into ordinary temporal experience suggests that a mindfulness practice that aims to attend to the "present moment" is problematic, if not experientially impossible. Time's linear flow-moving from the past, to the present, and into the future - proceeds forward along what seemingly appears as an unbroken continuity of points along a straight line. Events are partitioned or divided into either past memories or future hopes, expectations, fears, and wishes. What we call "reality" is located in the ephemeral and momentary "present," which is also continuously changing as the "next moment" arrives. The so-called present moment is located in a past-present-future temporal structure. This view takes for granted that time is an abstract container for actual moments, or units of time, which are arranged in a linear progression. This view (and lived experience) of time reduces it to an index and background factor; objectified time feels like an external, inexorable, and compelling force bearing down on us.

Our realm of experience then appears to be completely confined to, and happen within, the realm of linear time, where events unfold in a predictable sequential order, moving inexorably forward from the past, to the present, and into the future. Conditioned existence - the underlying temporal order of third-level suffering - appears absolutely real, and the only pattern we know. Because we act as if linear time is absolute, we "go along with it," enmeshed in this serial order and conditioned by it. While we are aware of "psychological time," the time of the "real world" is taken to be objective and fixed.

Indeed, the whole of our lives seems to be defined and confined to living within this linear temporal nexus. The passage of time in this linear temporal order is such that it appears to be moving by us like a river, with ourselves as located as distant bystanders on the river's bank. This temporal perspective positions us in the fleeting present moment, as if we were independent agents, or "bystanders" to time's sequential flow. It is this underlying sense of impermanence that threatens our sense of identity; time often feels like a hostile and alien force. This transitory linear temporal order is the realm of suffering, where all phenomena are conditioned, arising and passing away. And suffering is contingent on this temporal structure, where we often feel like a victim of time's relentless and feverish pace. Our sense of mortality looms large as linear time's inexorable momentum leads eventually to our personal death.

Elaborating on the suffering and damage from this lived view of time, Tarthang Tulku (1977, p. 128) stated:

Lived time goes too quickly; we never have enough of it. Thus, fulfillment is hard to obtain. This issue is not whether clock-time in this realm is faster or slower than in some larger space. It is that we have little capacity for opening to the infinity that "time" really offers and communicates. We do not let satisfaction be a reality. We try to achieve it in the future, to capture it and tie it down, making it a "present". Under such circumstances, we experience great tension and pressure. (italics in original).

Therapeutic mindfulness attempts to alleviate suffering experienced within this lived view of time by reducing thoughts and ruminations of the past and future, which keeps us from being in the present moment. Mindfulness practice is a way to help us attend more to the present moment, because that is where life supposedly really happens. However, even if we succeed to attending more to the present moment by reducing obsessive-compulsive thinking about the past and future, we are still subject to the flow of temporal change.

Therapeutic mindfulness also presupposes the observing subject is located at a position "here," who is instructed to pay attention to "the present" located over "there." The present moment is viewed as a graspable existent, that is, as a place or location in which to relocate one's attention. To "be here now" amounts to a sort of mental gymnastics - an attempt to relocate, or colocate, the "here" of the subject and the "there" of the now in one place. In this schema, the position of the observing subject is taken for granted; its job is to "be mindful" by grabbing hold of what amounts to a perpetual moving target - the present moment - and relocate it "here," where the "I" is supposedly located (Tarthang Tulku 1977).

Therapeutic mindfulness urges us to "live in the present moment" and to try to live mindfully, by "being here now." However, this heavy emphasis on locatedness subtly reinforces an achievement and self-orientation, as we are constantly in a mode of self-surveillance, checking up on our selves, gauging our progress and ability (or, more often than not, inability) to "be present." Tarthang Tulku (1977, p. 85), a Tibetan Buddhist lama, whose visionary and secular teachings on time, space, and knowledge offers a cogent critique on this mode of "be here now" mindfulness:

The popular meditative injunction to "Be here now" is seen from the Great Space perspective as probably misleading. On the one hand, it might be interpreted as invoking the ordinary sense of "here" and "the present". 
On the other, it might seem to refer to a kind of fleeting, immaculate sensum-like "here" which must be apprehended. Such orientations are a perpetuation of the restrictive focal setting and its emphasis on locatedness, etc.

There may also be an achievement and self-orientation involved, to the effect that we are urged to try to "be here", or to capture something close at hand. Or we might be reassured that everything is fine and that we should just "let things be". In either case, the immediate presence "here" of Great Space, and a true "opening" to it, are both being missed by clinging to a small focal setting counterparts, which are actually counterfeits.

For Tarthang Tulku, Great Space is not localizable as it is ground of all existence, transcending conventional dichotomies, opaque surfaces and boundaries, such as a "self vs. world," "subject-knowing-object." If we look more closely at the instruction to "pay attention to the present moment," we will quickly discover that such an activity is entangled in conventional dichotomies, particularly that of a subject/ observer attempting to know a mental object (the present moment). Therapeutic mindfulness practice instructs the client to purposefully pay attention to a moment designated as "the present." The client soon discovers rather quickly, that what was deemed the present moment has already shifted, becoming the past. Even the act of paying attention itself requires time or duration. By the time such attention occurs, the moment labeled as the present has already passed away. Approached in this way, mindfulness practice can, on the one hand, degrade to a frustrating and futile exercise; on the other hand, become an effortful activity "to be in the present," to grasp or freeze "present-centered" experience, as if this were the ultimate the goal of mindfulness practice.

Batchelor (2009, p. 1), a leading spokesperson for the Secular Buddhist movement, concurs that such a fixation on the present moment is misdirected:

I would argue that there is really no present moment. The present moment is one of these things that Buddhists have become terribly attached to. If you think about it, you try to find the present moment, you will never find anything. The present moment is actually just a concept; it can be a very useful, strategic concept ... I will often say when instructing in meditation, "Stay in the present moment." But I don't mean by that, try to find this elusive thing called the present moment and stay in it. It's basically a way of saying, Don't get caught up in the unknown future. Don't get caught up in reminiscing about the past. But confront the situation at hand. And the situation at hand is always unfolding. It's fluid. It's like water, it's like a stream. Things are constantly impacting your senses, constantly bubbling up in your thoughts, constantly emerging as emotions and feelings; it's always in motion, it's moving. And it's such a mobile experience that notion of 'The present moment' really has no place there. There's no point really. So, every situation that occurs, and you could call it 'at the present moment' if you wish, but it's basically an unfolding of events that is calling forth an appropriate response. And in this sense, it's always in time.

In many respects, "being in the present moment" has become the holy grail of therapeutic mindfulness. Zen teacher and therapist, Bazzano (2013), goes so far to say that the reification of the present moment has become the magical telos of secularized mindfulness practice. And it is hard to not hear the voices of Ram Dass (Be Here Now) and Eckhardt Tolle (The Power of Now) in most current descriptions of mindfulness, whether clinical or New Age - as they share a common predilection to sacralize the present moment. A more recent variation on this theme is MBSR trainer, Elisha Goldstein's book, The Now Effect. Brazier (2013) refers to this fixation on the present moment in mindfulness practice as "here-and-now-ism," the latest pop philosophy echoed by the media. Mindfulness has almost become synonymous with "being in the present moment," a cliché repeated ad nauseam.

"Here-and-nowism," however, is not only a modern phenomena - it was quite prevalent in 8th century China, promoted to the laity as a meditation method that promised quick results, with no requirements for doctrinal study or ethical training. As Buddhist scholar Sharf (2013) noted, early Zen patriarchs conceived meditation as an intense immersion in the flow of the here-and-now in order to foster a nonreactive, nonconceptual, and nondiscursive awareness, leading to a deep state of inner stillness. Zen reformers such as Dahui and later Hakuin in Japan, however, castigated such methods on the grounds that they easily lead to an imbalanced state of "meditation sickness," in which case the meditator becomes attached to a dull stillness or peaceful bliss states, with little concern for the suffering of the world.

In this respect, the instruction to pay attention to the present moment, and a conception of mindfulness that aims for the subject to "be in the present," can in actuality lead to a freezing effect by an attempt to shut down experiential time and the passage of ordinary time. The direction of attention to one momentary object probably accounts for its temporary therapeutic and calming effects, but it does not lead to any fundamental or significant change in the way the temporal order is viewed and experienced.

In contrast to MBSR's view of the present moment as a meditative object, fetishized as a mode for intensifying ordinary sensory experience, the Theravada Buddhist tradition employs mindfulness quite differently. While therapeutic mindfulness affirms and enhances appreciation of present 
moment experience, Theravada insight meditation enhances clear seeing into the nature of all conditioned existence - that which arises and passes away in the linear temporal order - as dukkha and unsatisfactory. Mindfulness is not employed as a method to heighten aesthetic appreciation for everyday events and objects, but to see beyond conventional appearances, that is, to apprehend and see clearly into the ultimate nature of conditioned phenomena. The present moment, like any other mental object, is seen for what it actually is-impermanent, unsatisfactory, and lacking self-nature. Insight meditation (or vipassana) in the Theravada tradition aims to "see things as they truly are," and in this case, it is insight into seeing the three ultimate characteristics of phenomena (annica, anatta, dukkha). All formations are inconstant and unsatisfactory: sabbe sankhara annica. Such direct seeing into the three characteristics is also seeing into temporal structure of thirdlevel suffering. This is deep seeing into the First Noble Truth. Complete freedom from suffering, or awakening, is unconditioned by the temporality of change.

In the case of the Burmese insight meditation method developed by Mahasi Sayadaw, bare mindfulness of the present is the starting point of the practice, but with the progress of the practice, the student is guided into the stages of insight according to the classical model laid out in texts like the Patisambhidamagga and the Visuddhimagga (Bodhi 2014). Valorization of the present moment is also curiously absent from the Pali Canon, the early corpus of Buddhist teachings. However, there is one passage in the Bhaddekaratta Sutta (A Single Excellent Night), in the Majjhima Nikaya (MN:131), that mentions that importance of applying insight into the urgency of seeing clearly into the fleeting nature of worldly existence (Ñanamoli \& Bodhi, 2009). The relevant passage states:

Let not a person revive the past

Or on the future build his hopes;

For the past has been left behind

And the future has not been reached.

Instead with insight let him see

Each presently arisen state;

Let him know that and be sure of it,

Invincibly, unshakably.

Today effort must be made;

Tomorrow Death may come, who knows?

No bargain with Mortality

Can keep him and his hordes away,

But one who dwells thus ardently,

Relentlessly, by day and night-

It is he, the Peaceful Sage has said,

Who has had a single excellent night.

(p.1039)

The contemporary Western Theravada Buddhist monk, Thanissaro Bhikkhu, points out that this passage is not describing a form of mindfulness that it is simply content with being in the present moment. Rather, this sutta is stressing the importance of the cultivation of insight, or seeing clearly (vipassati) each "presently arisen state" as fabricated and the need to develop dispassion for those fabrications. This includes the fabricated nature of the present moment. Moreover, the sutta goes on to emphasize the urgency of doing so, expressed as effort or ardency. This is a different matter than merely "staying in the present moment" or "being with experience" or accepting presently arising states nonjudgmentally. Rather, it means cultivating the wisdom to discern unskillful states of mind and behaviors, with the right intention of abandoning them.

In contrast, therapeutic and problem-solving mindfulness relate to our changing experiences by radically accepting and appreciating them, or milking them of their intensity or aliveness. Gilpin (2008) notes that in MBSR and MBCT, the breath is also used "as a means to relate differently to ones thoughts." Therapeutic mindfulness, as I alluded to earlier, is consonant with Buddhist values, as its aim is to reduce firstlevel suffering through symptom reduction. However, that is where its efficacy currently stops. Therapeutic mindfulness is not directed (nor should it be expected) to cultivating the penetrating wisdom and insight for seeing the true nature of phenomena, particularly the nature of the self. Rather, therapeutic mindfulness encourages the self to "be with" experience differently, and may actually reinforce a stronger sense of the self-as-active agent. Gilpin (2008, p. 243) elaborates on this point, as he stated:

Rather than encouraging the meditator to see through the illusion of the Self which is "observing" phenomena, its language implies such a position can be adopted, and by doing so one can enhance one's control of (particularly negative) mental and emotional experiences. At a subtle level, such habitual positioning may actually reinforce one's sense of self such that, if one were to continue practicing beyond a course (as MBCT encourages), the very progress such practices are designed to facilitate on the Buddhist path would be blocked by an unrealistic view or assessment of the meditative process (italics in original).

A key and unexamined presupposition underlying the varieties of therapeutic mindfulness is that the self (and by association "its mind") is an independent knower that has experiences - in this case, the experience of being in the socalled present moment. As Gilpin pointed out above, the whole frame in which a meditator is posited and instructed to pay attention, to actively know the present moment, amounts to an act of positioning. The self positions itself as the active agent - the one who knows - and assumes that its position is stable and continuous. This actually sets up a rather 
frozen and polarized subject-object field, with the self standing in a dualistic relation to its manifestations, including its thoughts, sensations, as well as the temporal flow. From this bystander perspective, the self appears to take a position outside the flow of time, and objectifies and conceptualizes moments in terms of their temporal referents - past, present, and future. In many respects, there is really nowhere else to stand except in the present moment, but when it becomes an objective referent, a goal to attain, we are in actuality severing our relationship to the dynamic of time.

Dōgen, an eminent 13th century Japanese Zen master and founder of the Soto school, was keenly aware of the limitations of this dualistic view of time. His understanding of temporality arises out of his practice of zazen and is expressed poetically in his fascicle $u j i$, which is one of the 96 chapters in his famous work, The Shobogenzo. Uji is roughly translated as "being-time," which for Dōgen, signifies that anything that happens $i$ time. Time is the nature of existence. In this essay, Dōgen makes such statements as "Time is existence, and existence is time" and "You must see all things in this world as time."

One of the fundamental tenets of Buddhist teachings is that all phenomena are impermanent, transient, and subject to change. Therefore, transience and time are closely related.

We may consider uji as "dynamic presencing," as time is never really separate or apart from the arising of a self or events. Dōgen provides a colorful illustrative passage to make this point in having us think about what "springtime" means from a temporal perspective. It is not that because it is spring that temperatures become milder, flowers bloom, and bees go about their business. It is because temperatures become milder, flowers bloom and bees go about their business, that we say it is spring. Moreover, for Dōgen, there are no "things" in time, which are then subject to impermanence and change, but that all beings are time; impermanence is not a curse but a blessing, or even the immediacy of awakening (Stambaugh 1990).

Dōgen recognizes two levels of time: the absolute and the relative. Dōgen provides an image of time as also being arrayed like peaks of a mountain range. While reality may only be experienced in the present moment, this is significant only because of the present moment's relationship to the past and future. Relative time is the time of our conventional world of cause and effect. This could be thought of as the horizontal dimension of time, where moments are causally connected. To live in dynamic presence, is to live in a present moment that vanishes as quickly as it arises, but it is a moment that has meaning and significance because of everything that came before it, and everything that will follow it. For Dōgen, living an awakened life is not only living in the fullness of the present moment but also in maintaining a broad temporal awareness (surveying the mountain peaks) of the conventional world of causal continuity with the past and future. Because the realm of samsara, dukkha, suffering is in horizontal dimension of time, awakening is not an escape to the absolute but a nondualistic embrace of both dimensions - the absolute and the relative - simultaneously.

These brief comments on Dōgen's Uji do not do justice to the breadth and depth of his teaching, but it should be quite apparent by now that he presents a very different view of the present moment than that found in MBSR and therapeutic mindfulness techniques. These therapeutic modalities are limited to focusing attention on the present moment in the horizontal dimension of time, with little questioning or challenging of the linear temporal order. Dōgen, however, expands our vision of awakening by also revealing the absolute present, time-as-existence, which flows not in the horizontal dimension of ordinary linear time, but in the vertical dimension (Abe 1992). This flow does not amount to ordinary passage, or a passing away, but a deepening presence in what might be crudely stated as an "expanded, trans-temporal present" (Abe 1992, p. 99). As Dōgen poetically stated:

It (time) flows from today to tomorrow. It flows from today to yesterday, it flows from yesterday to today, from today to today, from tomorrow to tomorrow. It is as if you were sweeping your gaze over one continuous fabric of time. Past time and present time do not accumulate, and future time does not deplete.

Thus, for Dōgen, the present moment in relative time is spatially located in a horizontal flow, whereas the absolute present is dynamically present and unified. Expressing this latter and trans-temporal present, Dōgen stated: "Time seems to be beyond but it is now. Time seems to be over there, but it is now." In this respect, the trans-temporal present does not have a linear "from-to" structure; time does not really flow from the past to the present. Rather, we could say that all time flows from the present, and every point on the horizontal line of linear, relative time is unified with the absolute present. Awakening to dynamic time, we may feel it as flowing, but it does not pass away in the ordinary sense. If time were merely to pass away, we would be separate from time. In other words, the present "presences" but it is not located nor confined to a past-present-future causal nexus. Dōgen expresses these points quite eloquently:

Do not think that time merely flies away. Do not see flying away as the only function of time. If time merely flies away, you would be separated from time. The reason you do not clearly understand the time-being is that you think of time only as passing. In essence, all things in the entire world are linked with one another as moments. Because all moments are the time-being, they are your time-being. 
Horizontal time is also spatially ordered; it is a time characterized by dualistic separation. Time is in the background, and things (including ourselves as subjects) are in the foreground. Embodying this lived view, we see and feel that "things" are happening and changing in time. Again, this is due to the linear and serial order of a past, present, and future structure, which resembles a spatial-like container through which existence appears to come into being and then pass away. Indeed, we ordinarily experience time as moving in a series of discrete moments, moving from-to, in succession. While ordinary time seems to be characterized by this pastpresent-future nexus, Uji, being-time is timeless, a transtemporal present is unified with all moments.

As Heine (1985, p. 26) pointed out, "Dōgen no longer saw time in terms of sorrow, unchanneled urgency, boredom or longing; he found that each and every and any moment could be an existential occasion to realize Buddha-nature." The conventional "from-to" structure is not operative in the vertical dimension of the absolute present. Moreover, all goal orientation ceases when this absolute, trans-temporal present is realized through zazen. For Dōgen, awakening and practice are unified; meditative practice, zazen, is not a means to achieve some special state of awakening located in the future. Thus, in zazen, there is no fixation on the present moment, and no seeking for awakening. Indeed, there is nothing to be attained and no place to go. This could be experienced as eternal moment, a spontaneous manifestation of dynamic presencing, quite different from a view of the present moment that is embedded within a linear past-present-future nexus. The compulsive need to alter, fix, or change experience lessens dramatically. The picture of a standard "world out there" that is spread out, separate from the self drops away. Conversely, the notion of an independent, bystander-self, perched in some stable and fixed position, also drops away. There is a pervasive transcendence of "happening," "occurrence," and "experience." What remains is an uncontrived intimacy, a complete "non-going" or "non-happening," an absolute peace (Tarthang Tulku 1977, p. 183).

Therapeutic mindfulness functions within a specific (and taken-for-granted) understanding of temporality. This essay has exposed the myth of the present moment. It is outside the scope of therapeutic mindfulness approaches to provide participants with modes of inquiry to investigate the underlying temporality of suffering at the deepest levels of human consciousness. Therapeutic mindfulness approaches address and operate primarily on the first-level of suffering, with some initial inquiry into the second-level of suffering. As the field of secular and therapeutic mindfulness develops further, it may benefit from developing mindfulness-based approaches that investigate and challenge the temporality of suffering by turning to classic Buddhist teachings, the works of Zen master Dōgen, and the visionary teachings of Tarthang Tulku.

\section{References}

Abe, M. (1992). A study of Dōgen: His philosophy and religion. Albany: State University of New York Press.

Batchelor, S. (2009). On making a raft. Podcast recording at upaya Zen center. New Mexico: Santa Fe.

Bazzano, M. (2013). In praise of stress induction. European Journal of Psychotherapy and Counseling, 15(2), 174-185.

Bodhi, Bhikkhu (2014). Personal communication.

Brach, T. (2004). Radical acceptance: embracing your life with the heart of a buddha. New York: Bantam Books.

Brazier, D. (2013). Mindfulness reconsidered. European Journal of Psychotherapy and Counseling, 15(2), 116-126.

Dorjee, D. (2014). Mind, brain and the path to happiness: A guide to Buddhist mind training and the neuroscience of meditation. New York: Routledge.

Gilpin, R. (2008). Theravada Buddhism and mindfulness-based cognitive therapy. Contemporary Buddhism, 9(2), 227-251.

Heine, S. (1985). Existential and ontological dimensions of time in Heidegger and Dōgen. Albany: State University of New York Press.

Kaplan, C. T., Winget, E., Fisher, N., \& Britton, W. B. (2012). Adverse effects and difficult stages of the contemplative path. In Mind and life summer research institute: New frontiers in contemplative science. NY: Garrison.

Loy, D. (2000). Lack and transcendence: The problem of death and life in psychotherapy, existentialism, and Buddhism. Amherst: Humanity Books.

Nanamoli, B. \& Bodhi, B. (2009). The middle length discourses of the Buddha: A translation of the Majjhima Nikaya (4th ed.). Boston, MA: Wisdom Publications.

Sharf, R. (2013). Mindfulness or mindlessness: traditional and modern Buddhist critiques of "bare awareness". Video lecture Advanced Studies Institute lectures on Mindfulness in a Cultural Context, McGill University: https://blogs.mcgill.ca/tcpsych/tag/robert-hsharf/

Stambaugh, J. (1990). Impermanence is buddha nature: Dōgen's understanding of temporality. Honolulu: University of Hawaii Press.

Tulku, T. (1977). Time, space and knowledge: A new vision of reality. Berkeley: Dharma Publishing.

Vago, D. (2013). Mapping modalities of self-awareness in mindfulness practice: A potential mechanism for clarifying habits of mind. Annals of the New York Academy of Sciences, 1307, 28-42.

Vago, D., \& Silbersweig, D. A. (2012). Self-awareness, self-regulation, and self-transcendence (S-ART):A framework for understanding the neurobiological mechanisms of mindfulness. Frontiers in Human Neuroscience, 6, 1-30. 